\title{
Aplicabilidad de la acción extraordinaria de protección frente a la decisión sobre competencia: análisis a la luz de las recientes decisiones de la Corte Constitucional
}

\author{
Andrés Larrea Savinovich* \\ Juan Martín Alarcón Peralta** \\ Recibido/Received: $31 / 07 / 2020$ \\ Aceptado/Accepted: 18/09/2020
}

\begin{abstract}
Sumario: 1. Introducción. 2. El principio kompetenz-kompetenz en arbitraje. 3. Decisiones recientes de la Corte Constitucional. 3.1. La casa en orden. 3.2. Caos procesal. 3.3. Al final una luz...; 4. Recursos disponibles frente a la declaratoria de competencia. 4.1. Sobre la declaratoria de competencia como un auto definitivo...; y, 5. Acciones constitucionales vis a vis el principio de no interferencia judicial en arbitraje. 6. Conclusión.
\end{abstract}

Resumen: Por mandato del artículo 22 de la Ley de Arbitraje y Mediación (LAM), una vez constituido el tribunal de arbitraje, se fijará el día y hora para la realización de la audiencia de sustanciación en la que, entre otras cosas, los árbitros resolverán sobre su propia competencia. Este principio de

* Asociado Senior en Tobar ZVS Spingarn. Secretario arbitral de la Cámara de Comercio de Quito, el Centro Internacional de Arbitraje y Mediación y el Centro de Arbitraje de la Cámara de la Construcción. Abogado por la Universidad de las Américas. LL.M. por McGill University. Correo electrónico: alarrea@tzvs.ec

** Asociado en Tobar ZVS Spingarn. Abogado por la Universidad San Francisco de Quito. Asociado ordinario en la Asociación Arbitraje Alumni. Correo electrónico: jmalarcon@tzvs.ec

A. Larrea Savinovich \& J. M. Alarcón Peralta, "Aplicabilidad de la acción extraordinaria de protección frente a la decisión sobre competencia: análisis a la luz de las recientes decisiones de la Corte Constitucional", Revista Ecuatoriana de Arbitraje, No. 11, 2020, pp. 21-44. 
derecho internacional reconocido como kompetenz-kompetenz es uno de los pilares fundamentales en la práctica del arbitraje moderno. Pero, ¿qué sucede si un tribunal se declara competente sin serlo? Si bien la LAM guarda silencio respecto a la posibilidad que tienen las partes procesales de impugnar una decisión sobre competencia, este artículo explora la aplicabilidad de la acción extraordinaria de protección como mecanismo para atacar esta resolución por ser violatoria a lo ordenado por el artículo 76 de la Constitución (derecho a ser juzgado por un juez competente). Hay que tener presente que la Corte Constitucional en dos decisiones recientes (31-14EP y 323-13-EP) clarificó los casos en los que proceden este tipo de acciones constitucionales en procesos de arbitraje, cómo se diferencian respecto de las acciones de nulidad y sobre la necesidad de agotar la acción de nulidad previo a la interposición de una acción constitucional. Sin embargo, estas decisiones judiciales parecen haber generado nuevas inquietudes respecto de la decisión de competencia de un tribunal incompetente y la posibilidad de impugnarla a través de una acción extraordinaria de protección.

Palabras Clave: arbitraje, acciones constitucionales, acción extraordinaria de protección, competencia.

\section{Applicability of the extraordinary action of protection to challenge the decision on competence: analysis in light of the recent Constitutional Court decisions}

Aвstract:Pursuant to article22 of the Arbitration and Mediation Law (LAM), once the tribunal has been constituted, they will set a date and time for the initial hearing, in which, among other things, the arbitrators shall rule on their own competence. This principle of international law known as kompetenz-kompetenz is one of the fundamental pillars of modern arbitration. But what 
happens if a non-competent tribunal rules to have competence on the matter? The LAM is silent on the possibility for the parties to challenge a decision on competence. This article explores the applicability of the extraordinary protection action as a mechanism to challenge the decision in which a tribunal declares to have competence in violation of article 76 of the Constitution, that recognizes the right to be judged by a competent authority. It is worth noting that the Constitutional Court in two recent decisions (31-14-EP and 323-13-EP) clarified the cases in which these types of constitutional actions are applicable in arbitration, how they differ from actions to set aside an award and on the necessity to file an annulment action before filing an extraordinary protection action. However, these rulings created new concerns regarding the competence decision and what are the possibilities to challenge it through an extraordinary action of protection.

KEYWORDs: arbitration, constitutional remedies, competence.

\section{INTRODUCCIÓN}

La LAM manda que el tribunal de arbitraje tiene la facultad exclusiva para decidir sobre su propia competencia. El artículo 22 dispone con norma de imperio que esta decisión debe hacerse en la audiencia de sustanciación, aún cuando alguna de las partes haya presentado excepciones jurisdiccionales ${ }^{1}$. Respecto de la decisión de competencia, la LAM no hace mención a ningún tipo de recurso disponible a favor de la parte procesal que quiera impugnarla. No obstante, hay que tener presente que la Constitución es la norma suprema en la legislación ecuatoriana y, por lo tanto, las decisiones expedidas dentro del sistema arbitral, aún siendo este último un mecanismo alternativo de solución de conflictos, deben ajustarse a lo que la Constitución manda.

1. Ley de Arbitraje y Mediación, Artículo 22, RO No. 417, 14/12/2006. 
El artículo 76 numeral 7 literal k de la Constitución garantiza el derecho que tienen todas las personas de ser juzgadas por un juez (o árbitro) competente 2 . Por lo tanto, si las partes de un contrato han convenido que en caso de diferencias derivadas de la ejecución del mismo se someterán a arbitraje, entonces serán los árbitros -no los jueces ordinarios- quienes deben declararse competentes para resolverlas. Asimismo, si una parte no ha consentido someter su disputa a arbitraje, no puede ser forzada por su contraparte a renunciar a la justicia ordinaria y someterse a un proceso arbitral.

Ahora bien, supongamos que A y B celebran un contrato en el que insertan una cláusula arbitral acordando que todas las disputas relacionadas con el mismo, salvo las que tengan que ver con el rubro " $X$ ", serán sometidas a arbitraje. Por permisión del artículo 5 de la LAM, las partes pueden someter todas o ciertas disputas que surjan entre ellas a arbitraje. En este caso, “ $\mathrm{A}$ ” y "B" decidieron someter la mayoría de sus disputas contractuales a arbitraje, con excepción de las disputas que tengan que ver con el rubro " $X$ ", las que están por fuera del alcance de la cláusula arbitral y que solo podrán ser ventiladas ante la justicia ordinaria por los jueces competentes. Sin embargo, imaginemos que " $\mathrm{A}$ ", con fundamento en la cláusula arbitral inserta en el contrato, decide demandar a " $\mathrm{B}$ " por una reclamación relacionada con el rubro " $\mathrm{X}$ ". Naturalmente, al contestar la demanda “ $\mathrm{B}$ " opone la excepción de incompetencia del tribunal indicando que las controversias relacionadas con el rubro " $X$ " fueron excluidas del arbitraje. No obstante, en la audiencia de sustanciación, el tribunal rechaza la excepción de " $\mathrm{B}$ " y resuelve declararse competente para conocer esta controversia, fijando un calendario procesal y ordenando la práctica de pruebas.

2. Constitución de la República del Ecuador, Artículo 76(7)(k), RO No. 449, 20/10/2008. 
En el ejemplo propuesto, el derecho constitucional de " $\mathrm{B}$ " de ser juzgado ante una autoridad competente, en este caso un juez y no un árbitro, ha sido afectado por la declaratoria de competencia del tribunal. Lo grave, es que "B" se verá obligada a someterse a un proceso arbitral al que no consintió, con todos los gastos y tiempo que esto implica. De igual manera, pretender que " $\mathrm{B}$ " espere hasta la conclusión del procedimiento arbitral y a la expedición del laudo para presentar una acción constitucional, resulta supremamente perjudicial, ya que esto demandaría ingentes recursos en tiempo y en dinero en la tramitación de un proceso inconstitucional proceso arbitral.

En este sentido, si bien la LAM guarda silencio respecto de los recursos que pueden plantearse en contra de una decisión de competencia, el artículo 94 de la Constitución permite interponer una acción extraordinaria de protección ante la Corte Constitucional en contra de sentencias o autos definitivos en los que se ha violado por acción u omisión derechos reconocidos en la Constitución ${ }^{3}$. Por lo tanto, la utilización de este remedio constitucional resulta ser la solución a este problema jurídico.

No obstante, la interposición de acciones constitucionales respecto de decisiones arbitrales ha generado mucha polémica ya que, a criterio de algunos expertos, estas podrían ser utilizadas como una "instancia adicional" y abrirían la puerta para una excesiva interferencia judicial. Si bien se han intentado anteriormente interponer acciones extraordinarias de protección en contra de declaratorias de incompetencia de un tribunal arbitral, no conocemos respecto de este tipo de acciones propuestas frente a una declaratoria de competencia. Por lo tanto, frente a la interposición de una acción extraordinaria de protección en contra de una decisión

3. Ídem, Artículo 94. 
de este tipo, el tratamiento por parte de la Corte Constitucional resulta incierto.

Además, hasta hace muy poco tiempo, aún existía una gran confusión respecto de las facultades de la Corte Constitucional para revisar decisiones arbitrales. Afortunadamente, con la expedición de las Sentencias No. 31-14-EP y No. 323-13EP, la Corte Constitucional aclaró muchas dudas respecto de este tema ${ }^{4}$. Sin embargo, aún existe un vacío respecto de la posibilidad de interponer una acción extraordinaria de protección frente a las decisiones de competencia expedidas por un tribunal de arbitraje no competente.

\section{EL PRINCIPIO KOMPETENZ-KOMPETENZ EN ARBITRAJE}

En la legislación ecuatoriana la jurisdicción y la competencia se reconocen como dos institutos jurídicos distintos. Al respecto, el Código Orgánico de la Función Judicial (COFJ) trata en su artículo 7 los principios de jurisdicción y competencia, y manda que "[1]a jurisdicción y la competencia nacen de la Constitución y la ley". A continuación, el COFJ se refiere a los árbitros diciendo que estos "ejercerán funciones jurisdiccionales, de conformidad con la Constitución y la ley"

Respecto a la jurisdicción, esta se encuentra definida en el artículo 159 del COFJ como la "potestad pública de juzgar y hacer ejecutar lo juzgado, potestad que corresponde a las juezas y jueces establecidos por la Constitución y las leyes, y que se ejerce según las reglas de la competencia. En relación con la competencia, esta se encuentra definida en el mismo cuerpo legal como "la medida dentro de la cual la potestad jurisdiccional está distribuida entre las diversas cortes,

4. Corte Constitucional del Ecuador, Sentencia No. 31-14-EP/19, Caso No. 31-14-EP, 19/112019; Corte Constitucional del Ecuador, Sentencia No. 323-13-EP/19, Caso No. 323-13-EP, $19 / 11 / 2019$.

5. Código Orgánico de la Función Judicial, Artículo 7, RO (S) No. 544, 09/03/2009. 
tribunales y juzgados, en razón de las personas, del territorio, de la materia, y de los grados" ${ }^{\prime}$.

Ahora bien, en materia arbitral es la LAM la que otorga a los árbitros la facultad exclusiva de resolver su propia competencia. Esta facultad es conocida como el principio rector del arbitraje moderno denominado kompetenz-kompeten $z^{7}$. Este principio de derecho internacional se encuentra claramente reconocido en la mayoría de legislaciones a nivel mundial así como en el artículo 16 de la Ley Modelo sobre Arbitraje Comercial Internacional de la Comisión de las Naciones Unidas para el Derecho Mercantil Internacional (Ley Modelo CNUDMI) en la que están inspiradas leyes como la LAM.

En concordancia con lo anterior, la LAM reconoce el principio de indubio pro arbitri, mediante el que, en caso de duda, se entiende que los jueces deben entender que el conflicto se encuentra sometido a arbitraje. Usualmente, dentro de un proceso judicial cuando el demandado opone la excepción previa de "existencia de convenio arbitral", los jueces derivan el conflicto a arbitraje para que sean los árbitros quienes resuelvan y decidan sobre su competencia9. Al respecto, la Corte Constitucional en Sentencia No. 0006-10-SEP-CC ${ }^{10}$, razonó que continuar con el procedimiento ante los jueces ordinarios a pesar de existir un convenio arbitral, derivaría en una clara violación del derecho al debido proceso. Esta acertada decisión de la Corte es importante para el desarrollo del arbitraje y garantiza que la justicia ordinaria no interfiera

\footnotetext{
6. Ídem, Artículo 159.

7. S. Llain AREnILla, "El rol del principio de "competence-competence" en la prevención de tácticas dilatorias en el arbitraje comercial internacional", Revista Colombiana de Derecho Internacional, No. 24, 2014.

8. A. JIJÓN ANDRADE, "Reconciliando el principio Kompetenz-Kompetenz con la autoridad supervisora de las cortes nacionales", Revista Ecuatoriana de Arbitraje, No. 6, 2014.

9. K. Andrade Quevedo, Los problemas derivados del Principio Kompetenz-Kompetenz en un régimen jurídico en el que no se ha perfilado adecuadamente su alcance, Tesis de Grado, Universidad San Francisco de Quito, 2007.

10. Corte Constitucional del Ecuador, Sentencia No. 0006-10-SEP-CC, Caso No. 0712-09-EP, $24 / 02 / 2010$.
} 
con la autonomía del proceso arbitral. Hay que tener presente, que, bajo el mismo criterio explicado en la sentencia, podemos concluir que, continuar con un proceso arbitral en el que los árbitros son incompetentes para conocer la controversia, resulta en una clara violación del derecho constitucional de toda persona a ser juzgado por una autoridad competente.

Como hemos dicho, el arbitraje es por su propia esencia convencional, esto significa, que para que pueda haber lugar a un proceso arbitral es necesario que las partes hayan acordado previamente en someter a resolución de árbitros esas diferencias. Por lo tanto, lo primero que el tribunal debe analizar es el convenio invocado por quien demanda para poder establecer si de él existe arbitraje y con él nace su propia competencia para resolver la disputa puesta en su conocimiento ${ }^{11}$. Legalmente, el momento procesal pertinente para que el tribunal tome dicha decisión es en la audiencia de sustanciación por mandato del artículo 22 de la LAM ${ }^{12}$. La legislación nacional no permite que los árbitros tomen esta decisión en otro momento. A diferencia de la LAM, la Ley Modelo CNUDMI sí permite que los árbitros decidan sobre su competencia en otro momento procesal (en un laudo, por ejemplo $)^{13}$.

En conclusión, el principio kompetenz-kompetenz garantiza el deseo de las partes de que las discrepancias surgidas entre ellas, inclusive las relacionadas con la validez, el alcance y la existencia del convenio arbitral sean resueltas por árbitros y no por la justicia ordinaria. Este principio es fundamental dentro del arbitraje moderno y sin él, difícilmente el arbitraje hubiera podido tener el desarrollo importante que

11. K. Andrade Quevedo, N. 9.

12. Ley de Arbitraje y Mediación del Ecuador, N. 1, Artículo 22. "Art. 22.- Una vez constituido el tribunal, se fijará día y hora para la audiencia de sustanciación en la que se posesionará el secretario designado, se leerá el documento que contenga el convenio arbitral y el tribunal resolverá sobre su propia competencia [...]".

13. Ley Modelo de la CNUDMI sobre Arbitraje Comercial Internacional (1985 con enmiendas de 2006). 
tiene en la actualidad. Sin embargo, el principio también conlleva una gran responsabilidad en los árbitros, quienes al momento de resolver sobre su competencia deberán estudiar cuidadosamente el convenio arbitral para determinar si son efectivamente competentes, o caso contrario, deberán optar por declinar su competencia a fin de que la discrepancia sea resuelta por los jueces ordinarios, según la materia y territorio al que corresponda ${ }^{14}$.

\section{Decisiones relevantes de la Corte Constitucional FRENTE AL ARBITRAJE}

\subsection{La casa en orden}

La anterior Corte Constitucional, expidió una serie de decisiones en materia arbitral que parecían esclarecer la procedencia de los recursos judiciales y constitucionales frente al arbitraje. Por un lado, en el año 2012 mediante la Sentencia No. 169-12-SEP-CC ${ }^{15}$ la Corte Constitucional rescataba la excepcionalidad de la acción extraordinaria de protección estableciendo como requisito previo, el agotamiento de la acción de nulidad. La única excepción a dicha regla fue cuando se demuestre que ni la acción de nulidad ni cualquier otro recurso ordinario fuese efectivo para detener la violación de derechos constitucionales.

En el año 2013 la Sentencia No. 123-13-SEP-CC ${ }^{16}$ estableció que los laudos arbitrales pueden y deben estar sujetos al control constitucional, ya que tanto en la justicia ordinaria como en los mecanismos alternativos de solución de conflictos, las

14. D. Andrade Álvarez, Aplicación del principio favor arbitralis en cláusulas patológicas, Tesis de Grado, Universidad del Azuay, 2015.

15. Corte Constitucional del Ecuador, Sentencia No. 169-12-SEP-CC, Caso No. 1568-10-EP, 26/04/2012.

16. Corte Constitucional del Ecuador, Sentencia No. 123-13-SEP-CC, Caso No. 1542-11-EP, 19/12/2013. 
decisiones que allí se expiden pueden derivar en violaciones a los derechos constitucionales. Parecía entonces que los caminos para recurrir un laudo arbitral estaban esclarecidos: las violaciones del debido proceso son materia de la acción de nulidad, y las violaciones constitucionales serán tratadas mediante acción extraordinaria de protección. Sin embargo, la práctica lo que produjo fue un abuso de la acción extraordinaria de protección que terminaba siendo una especie de última instancia, casi obligatoria dentro de los procesos arbitrales, ya sea directamente desde el laudo arbitral o posterior a la acción de nulidad. Esto, ocasionaba una interferencia judicial excesiva sobre el arbitraje y su autonomía y además afectaba la celeridad y la confidencialidad de los procesos que eran judicializados.

\subsection{Caos procesal}

Una de las decisiones judiciales más perjudiciales para el desarrollo del arbitraje nacional sucedió cuando la anterior Corte Constitucional en el año 2015, expidió la Sentencia No. 302-15-SEP-CC ${ }^{17}$. Esta sentencia buscaba robustecer la acción de nulidad y terminó desnaturalizando a la acción extraordinaria de protección. En resumen, se estableció tácitamente que las causales previstas por el artículo 31 de la LAM no son taxativas, puesto que además de estas se abrió la posibilidad de discutir mediante una acción de nulidad, asuntos relativos a la falta de motivación, así como la falta de competencia de un tribunal arbitral. En consecuencia, se abrió la puerta para una desmedida interferencia judicial en el arbitraje.

La Corte Constitucional anterior, justificándose en la protección del debido proceso, confundió a propios y extraños del mundo arbitral ya que las causales aceptadas

17. Corte Constitucional del Ecuador, Sentencia No. 302-15-SEP-CC, Caso No. 0880-13-EP, $16 / 09 / 2015$. 
por la Corte dentro una acción de nulidad de laudo arbitral, guardan relación con violaciones a derechos constitucionales: motivación (artículo 76 numeral 7 literal i ${ }^{18}$ ); y, juez competente (artículo 76 numeral 7 literal $\mathrm{k}^{19}$ ) y son ajenas a la naturaleza de una acción de nulidad. Como consecuencia de aquello, la Sentencia No. 302-15-SEP-CC ${ }^{20}$ logró saturar el sistema judicial con innecesarias y fútiles acciones extraordinarias de protección, ya que la incertidumbre sobre la acción de nulidad como prerrequisito a la acción extraordinaria de protección ocasionó inseguridad jurídica entre litigantes y jueces. En consecuencia, los usuarios del sistema arbitral se dedicaron a interponer acciones de nulidad, aún sin fundamento, simplemente para "cumplir" con un absurdo requisito previo para reclamar la violación de un derecho constitucional.

\subsection{Al final una luz}

Finalmente, el 19 de noviembre de 2019, la actual Corte Constitucional, se apartó del nefasto precedente y aclaró la eterna discusión sobre la acción de nulidad, la acción extraordinaria de protección y bajo qué circunstancias procede cada una de ellas. Sobre la necesidad de agotar con la acción de nulidad como prerrequisito de la acción extraordinaria de protección, los Autos de inadmisión No. 1867-18-EP'21 y No. 1204-18-EP 22 son claros. Si el motivo invocado se encuentra previsto en el artículo 31 de la LAM, es indispensable agotar la acción de nulidad; de lo contrario, se probaría que dicha acción no es la adecuada ni eficaz y por ende daría paso a una acción extraordinaria de protección directamente. Finalmente, lo que la Corte aclaró fue que si el motivo del reclamo de quien intenta una acción de nulidad está enmarcado dentro de las causales

18. Constitución de la República del Ecuador, N. 2, Artículo 76(7)(i).

19. Ídem, Artículo 76(7)(k).

20. Corte Constitucional del Ecuador, N. 17.

21. Corte Constitucional del Ecuador, Auto de inadmisión, Caso No. 1867-18-EP, 02/05/2019.

22. Corte Constitucional del Ecuador, Auto de inadmisión, Caso No. 1204-18-EP, 27/03/2019. 
previstas por el artículo 31 de la LAM, esa es la vía idónea. Caso contrario, lo que procede es una acción extraordinaria de protección. En este sentido y respecto del control judicial y el control constitucional de los laudos arbitrales, la Corte Constitucional expidió las Sentencias No. 323-13-EP y No. 03114-EP23, en las cuales estableció que el control judicial de una acción de nulidad, debe enmarcarse únicamente a lo previsto en el artículo 31 de la LAM, garantizando así, la aplicación del principio de intervención mínima y la alternabilidad del arbitraje.

Ahora bien, respecto del control constitucional, la Corte ha sido enfática en contrastar la "alternabilidad" y "voluntariedad" del arbitraje con la obligación de respetar y garantizar los derechos constitucionales. En virtud de ello es que se prevé el ejercicio de la acción extraordinaria de protección ante una violación a un derecho constitucional, como el debido proceso; siempre y cuando, el derecho procesal no conceda una acción eficaz y válida, como es el escenario propuesto en el presente artículo, por ejemplo.

\section{Recursos disponibles fRente a la declaratoria DE COMPETENCIA}

Después de analizar las sentencias de la Corte Constitucional sobre las decisiones de competencia, parecería ser que efectivamente es posible plantear una acción extraordinaria de protección frente a la declaratoria de no competencia por parte de un tribunal arbitral que ha declinado erróneamente su competencia. Sin embargo, en el supuesto contrario, cuando un tribunal arbitral se declara competente, sin serlo, por ejemplo cuando la cláusula arbitral no cubre la disputa puesta a su conocimiento, parece ser que ni la Corte Constitucional ni la doctrina local se han detenido a analizar

23. Corte Constitucional del Ecuador, N. 4. 
cuáles son las alternativas para impugnar dicha decisión. Finalmente, es una violación al derecho de toda persona no ser juzgado por un juez competente (artículo 76 numeral 7 literal k de la Constitución).

Si la Corte Constitucional ya ha admitido a trámite ${ }^{24}$ casos en los que se han interpuesto acciones extraordinarias de protección frente a una declaratoria de incompetencia, entonces lógicamente debería tener el mismo criterio frente a una declaratoria de competencia porque tanto la declaratoria de incompetencia de un tribunal competente como la declaratoria de competencia de un tribunal no competente, incurren en la misma violación y del mismo derecho, solo que desde el supuesto contrario.

Por otro lado, la Corte Constitucional en el Caso No. 054314-EP 25 iniciado por la compañía Quasar Náutica Expeditions S.A., aceptó una acción extraordinaria de protección, en la que uno de los argumentos principales era la expedición de un laudo arbitral por un tribunal de arbitraje incompetente. En ese proceso la Corte explicó que "[u]na de las garantías básicas que aseguran estas condiciones mínimas para tramitar un procedimiento es el derecho a ser juzgado por juez o autoridad competente" y además agregó que "[1]a referida facultad juzgadora de los árbitros tiene su límite en la competencia que se les otorgue, de acuerdo al ordenamiento jurídico en un principio y después en concordancia con lo convenido por las partes".

En consecuencia, parecería que a criterio de la Corte, la oportunidad para solucionar la problemática principal de este artículo (impugnar la declaratoria de competencia de un tribunal incompetente), sería con la interposición de

24. Corte Constitucional del Ecuador, Proceso 0638-17-EP, 06/06/2017.

25. Corte Constitucional del Ecuador, Sentencia 113-15-SEP-CC, Caso No. 0543-14-EP, $08 / 04 / 2015$. 
una acción extraordinaria de protección en contra del laudo arbitral. En concordancia, en la Sentencia No.323-13-EP / 19, la Corte se ratifica que "[e]xiste el control constitucional de laudos arbitrales en caso que estos violen el debido proceso" ${ }^{26}$, no obstante, nos apartamos parcialmente de este criterio. Si bien compartimos que la acción extraordinaria de protección es el mecanismo idóneo para la protección del derecho constitucional que se busca proteger (derecho a ser juzgado por autoridad competente), consideramos que la misma no debería interponerse con la expedición del laudo, sino en la declaratoria de competencia del tribunal que, como hemos explicado, ocurre en la audiencia de sustanciación por mandato del artículo 22 de la LAM.

Es importante tomar en cuenta que la interposición de una acción extraordinaria de protección requiere el cumplimiento de ciertos requisitos de procedencia para que sea admitida. Al respecto, es importante referirnos al artículo 94 de la Constitución que manda:

Art. 94. La acción extraordinaria de protección procederá contra sentencias o autos definitivos en los que se haya violado por acción u omisión derechos reconocidos en la Constitución, y se interpondrá ante la Corte Constitucional. El recurso procederá cuando se hayan agotado los recursos ordinarios y extraordinarios dentro del término legal, a menos que la falta de interposición de estos recursos no fuera atribuible a la negligencia de la persona titular del derecho constitucional vulnerado ${ }^{27}$.

Por su parte, la Ley Orgánica de Garantías Jurisdiccionales y Control Constitucional manda:

Art.58.-Objeto.- La acción extraordinaria de protección tiene por objeto la protección de los derechos constitucionales y debido proceso en sentencias, autos definitivos, resoluciones con fuerza de sentencia, en los que se hayan

26. Corte Constitucional del Ecuador, N. 4.

27. Constitución de la República del Ecuador, N. 2, Artículo 94. 
violado por acción u omisión derechos reconocidos en la Constitución" ${ }^{28}$.

Este artículo presenta tres elementos que deben cumplirse para que se pueda plantear una acción extraordinaria de protección: (i) que exista una violación a un derecho constitucional; (ii) que dicha violación derive de una sentencia, un auto definitivo o una resolución con fuerza de sentencia; y, (iii) que se hayan agotado los recursos ordinarios o que los mismos no sean apropiados para la protección del derecho constitucional violado. A continuación, pasamos a analizar cada uno de estos requisitos para determinar la procedencia de una acción extraordinaria de protección en contra de una declaratoria de competencia por parte de un tribunal incompetente.

El primer requisito se cumple porque, como hemos manifestado a lo largo de este artículo, y lo ha indicado la Corte Constitucional en Sentencia No. 323-13-EP/19, “[1] os árbitros en todo momento están obligados a observar y hacer respetar los derechos y garantías constitucionales" ${ }^{29}$. Por lo tanto, una declaratoria de competencia de un tribunal incompetente vulnera el derecho constitucional consagrado en el artículo 76, numeral 7, literal k, de la Carta Magna. Al ser una violación al debido proceso, "no se concreta en las afirmaciones de una ley, [...] se proyecta más en los derechos [...] que se han de preservar con la aspiración a un orden más justo" ${ }^{30}$.

El segundo requisito, lo analizaremos más adelante, ya que consideramos que es el que más profundidad amerita. Respecto del tercer requisito, esto es, el agotamiento de recursos ordinarios, conforme hemos indicado, la LAM guarda silencio sobre cuáles son los recursos disponibles

28. Ley Orgánica de Garantías Jurisdiccionales y Control Constitucional, Artículo 58, RO (S) No. $52,22 / 10 / 2009$.

29. Corte Constitucional del Ecuador, N. 4.

30. O. A. Gozaíni, "El Debido Proceso en la Actualidad” en G. Hernández Villarreal (Ed.), Perspectivas del Derecho Constitucional, Editorial Universidad del Rosario, 2007, p. 170. 
para atacar una declaratoria de competencia. En vista de que no existen recurso disponibles para "agotar", entonces se cumple también este requisito. Frente a una errada decisión de competencia, el único remedio apropiado, eficaz y disponible es la acción extraordinaria de protección porque justamente se trata de proteger un derecho constitucional que no puede ser protegido por ningún otro mecanismo. La acción de nulidad, por ejemplo, implicaría primero forzar a la parte cuyo derecho se quiere proteger a litigar su disputa en arbitraje hasta obtener un laudo, con los costos y tiempo que esto implica, y además, la misma tiene causales taxativas para su presentación y que están establecidas en el artículo 31 de la LAM. Ninguna de esas causales, se enmarcan con la problemática descrita. En este sentido OYARTE menciona "[c] omo se observa, no todas las violaciones al debido proceso se contemplan como causa de nulidad del laudo arbitral y, notoriamente, la acción de nulidad no tiene por objeto analizar si ese laudo resulta violatorio de derechos fundamentales" ${ }^{\prime \prime 1}$. Esto guarda armonía con la Sentencia No. 323-13-EP/1932 de la Corte Constitucional en la que ha explicado que la acción de nulidad solo es procedente cuando la situación se enmarca dentro de las causales específicamente descritas en la ley. La competencia del tribunal, no es una de ellas.

\subsection{Sobre la declaratoria de competencia como un auto definitivo}

Quizá el punto más álgido del debate, sea determinar si la declaratoria de competencia constituye un auto definitivo. La jurisprudencia de la Corte Constitucional ha coincidido en que un laudo es una resolución con fuerza de sentencia ${ }^{33}$ expedida por un árbitro que ejerce funciones jurisdiccionales. Pero, ¿qué

31. R. Oyarte Martínez, Acción Extraordinaria de Protección, Corporación de Estudios y Publicaciones, 2017, p. 256.

32. Corte Constitucional del Ecuador, N. 4.

33. Corte Constitucional del Ecuador, N. 15. 
pasa con las declaratorias de competencia? Es claro que no son sentencias, ni tampoco resoluciones con fuerza de sentencia, pues no tratan el fondo del proceso. ¿Podemos afirmar que son autos definitivos?

Antes de responder esta pregunta, vale la pena revisar la naturaleza de la acción extraordinaria de protección, la cual conforma un proceso autónomo, la cual no configura una instancia; pues la Corte realiza un "juicio de control constitucional, cuyo objeto es la protección primordial del interés público y subsidiariamente los intereses privados, tutelando los derechos fundamentales consagrados en la Constitución" ${ }^{34}$. Ahora bien, este tipo de acción cabe sobre los autos definitivos y "si bien la Corte Constitucional en un inicio indicó que el auto definitivo es aquel que pone fin al proceso, posteriormente se dieron variantes jurisprudenciales notorias en las que, incluso, se señala como procedente la impugnación de autos interlocutorios a través a acción extraordinaria de protección o los emitidos ordenando medidas cautelares" ${ }^{35}$.

El diccionario de la Real Academia Española sostiene que el término definitivo significa "que decide, resuelve o concluye". Si bien la decisión de competencia no decide, resuelve o concluye sobre el fondo de la controversia, no es menos cierto que sí resuelve sobre la competencia que tienen los árbitros al amparo del convenio arbitral para impartir justicia. Asimismo, como explicamos anteriormente, los árbitros resuelven sobre su competencia en la audiencia de sustanciación y frente a esa decisión definitiva, no existe ningún tipo de recurso disponible. Naturalmente, en el laudo arbitral, usualmente la mayoría de los tribunales arbitrales dedican un acápite a la "competencia", pero en realidad no están resolviendo ni decidiendo ni concluyendo nada, sino que únicamente están ratificando la decisión contenida en el acta de audiencia de

34. G. Armienta Calderón, Teoría General del Proceso, Porrúa, p. 355-356.

35. Ibídem, p. 338. 
sustanciación celebrada varios meses atrás y, por lo general, se limitan a indicar que la misma tiene efectos definitivos e irrevocables de conformidad con el principio kompetenzkompetenz. Por lo tanto, si esa declaratoria de competencia tuvo efectos definitivos, podemos concluir que se trata de un auto definitivo porque las partes no tuvieron ningún tipo de recurso disponible para resistirse al mismo.

La interposición de una acción extraordinaria de protección en contra de un laudo arbitral expedido por un tribunal incompetente, en realidad resulta un remedio poco eficaz para proteger el derecho constitucional vulnerado. Primero, porque estaríamos forzando a una parte a litigar ante una autoridad incompetente y exigiendo que espere hasta la expedición del laudo para recién entonces reclamar la protección de su derecho. Segundo, porque el laudo solo contiene una confirmación de la declaratoria de competencia, que no puede ser entendida como el auto definitivo que generó la vulneración del derecho. Al contrario, el derecho constitucional se vulneró varios meses antes de la expedición de ese laudo, concretamente en la audiencia de sustanciación. Por lo tanto, el momento oportuno para proteger el derecho vulnerado e interponer la acción extraordinaria de protección es justamente en la fecha en la que se expidió el auto definitivo (declaratoria de competencia). Finalmente, sacrificar la tutela efectiva de un derecho constitucional violentado por un requisito de forma, parecería contradictorio al espíritu de la Carta Magna y la naturaleza de la acción analizada. No por nada se asevera con frecuencia que "las cosas en derecho son por sus efectos, mas no por su nombre". En este sentido, el auto definitivo que declara la competencia del tribunal arbitral constituye, por sus efectos, un auto definitivo; toda vez que el tribunal resuelve sobre su competencia, elaborando un criterio -inimpugnable- respecto del cual no se vuelve a discutir dentro del proceso arbitral. 
En conclusión, consideramos que la declaratoria de competencia de un tribunal incompetente cumple con todos los requisitos ordenados por la ley para ser admitida. Es importante tener en cuenta que la admisión de una acción extraordinaria de protección sobre la resolución de competencia de un tribunal arbitral no suspende el trámite del proceso arbitral ${ }^{36}$. Motivo por el cual, dicha acción no se convertiría en una estrategia para entorpecer infundadamente la conducción del arbitraje.

\section{ACCiOnes CONSTITUCIONAles VIS A VIS El PRINCIPIO DE NO INTERFERENCIA JUDICIAL EN ARBITRAJE}

Es un principio de derecho internacional ampliamente reconocido que, cuando las partes deciden someter sus diferencias a arbitraje también están excluyendo a la justicia ordinaria de entrometerse en la resolución de su disputa (efecto negativo del convenio arbitral) ${ }^{37}$. Este principio es conocido como "no interferencia en arbitraje" o "protección de arbitraje". Al respecto, CAIVANO señala que:

[1]a jurisdicción que detentan los árbitros está sostenida por el ordenamiento legal que respalda la institución del arbitraje, permitiendo que los particulares, dentro de la esfera de la libertad negocial, sustraigan determinadas contiendas de la jurisdicción de los jueces estatales para otorgarlas a otros particulares ${ }^{38}$.

En resumen, este principio busca que la intervención de los órganos judiciales en arbitraje sea limitada, restrictiva y en respeto de la autonomía del proceso arbitral, porque si las partes ya decidieron someter sus controversias a arbitraje entonces lo lógico es pensar que su intención fue apartarlos

36. Ley Orgánica de Garantías Jurisdiccionales y Control Constitucional, N. 28, Artículo 62.

37. J. Figueroa Valdés, "La autonomía de los árbitros y la intervención judicial", Revista de la Pontificia Universidad Católica del Perú, 2014.

38. R. J. Caivano, Arbitraje, 2da Ed., Ad-Hoc S.R.L., 2000. 
de la controversia ${ }^{39}$. De conformidad con la LAM, la justicia ordinaria tiene facultades limitadas para intervenir en un proceso arbitral. Por ejemplo, los árbitros pueden solicitar a los jueces su auxilio para la ejecución de una medida cautelar. Sin embargo, el rol de los jueces en el arbitraje es muy restrictivo y como hemos dicho, debe favorecer el principio indubio pro arbitri incluso en caso de duda.

Por mandato de la LAM, el arbitraje solo está sujeto a control judicial de forma posterior a través de una acción de nulidad. Al respecto, el artículo 31 de la LAM de forma categórica manda que el laudo arbitral podrá ser revisado por los jueces (Presidente de la Corte Provincial que corresponda) bajo determinadas causales taxativas ${ }^{40}$. Esto significa, que el Presidente de la Corte Provincial solo está facultado a revisar aspectos formales de un laudo bajo las causales contempladas en la LAM. Por lo tanto, las cortes provinciales no podrán inmiscuirse en los méritos de la disputa, valorar prueba nuevamente o entrar a discutir la motivación del laudo arbitral. Si bien existen decisiones judiciales en este sentido, hay que tener presente que las mismas han sido expedidas en franca contradicción con lo dispuesto por la LAM.

Ahora bien, una cosa es sostener que la justicia ordinaria debe estar apartada del proceso arbitral para garantizar su autonomía, y, otra distinta, es afirmar que por la alternabilidad del proceso arbitral entonces este no está sujeto a ningún tipo de control. Sostener lo segundo, sería permitir que en un arbitraje se violen todo tipo de derechos constitucionales y garantías al debido proceso sin ningún tipo de responsabilidad posterior. Como hemos dicho, en el arbitraje se deben respetar los derechos consagrados en la Constitución ${ }^{41}$, pues los métodos alternativos de solución de conflictos no pueden escapar del

39. M. Castillo Freyre et al., "Principios y derechos de la función arbitral", LEX, No. 15, 2015.

40. Ley de Arbitraje y Mediación, N. 1, Artículo 31.

41. Corte Constitucional del Ecuador, N. 15. 
control constitucional. La pregunta es, ¿qué pasa si no es así? En estos casos, deberíamos concluir que dichas decisiones serán susceptibles de ser revisadas mediante acciones extraordinarias de protección cuyo objetivo es precisamente la protección de derechos constitucionales violados que no tengan otro mecanismo o recurso para su protección.

La interposición de acciones constitucionales no constituye en sí una violación al principio de no interferencia judicial en el arbitraje, en la medida en la que estas no sean usadas como mecanismos para entorpecer injustificadamente la tramitación de un proceso arbitral o como una "instancia adicional" de participación judicial. Por lo tanto, la clave está en utilizar estas acciones constitucionales de forma correcta, entendiendo cuándo proceden y en qué casos deben ser utilizadas para evitar que una decisión arbitral, como la declaratoria de competencia de un tribunal, viole derechos constitucionales.

\section{Conclusiones}

Las acertadas decisiones de la Corte Constitucional dentro de los Casos No. 323-13-EP y No. 031-14-EP constituyen un aporte positivo para el desarrollo del arbitraje local porque zanjan de una vez por todas la utilización de recursos judiciales y constitucionales previstos por el ordenamiento jurídico frente a las decisiones adoptadas en el sistema arbitral. A su vez, estas decisiones han aliviado la gran carga de acciones extraordinarias de protección, sin sustento, que eran planteadas en contra de decisiones arbitrales ante la Corte Constitucional. Si bien estas decisiones sugieren que en una acción extraordinaria de protección es posible tratar asuntos sobre la competencia del tribunal arbitral, es importante señalar que las mismas hacen referencia a los laudos, mas no a las decisiones de competencia. Por lo tanto, por un lado, estas sentencias garantizan la correcta aplicación del artículo 31 
de la LAM, lo que protege el derecho a la seguridad jurídica, pero, por otro lado, reflejan el vacío legal, jurisprudencial y doctrinario que existe frente a las decisiones de competencia de un tribunal de arbitraje que es incompetente para conocer una disputa, lo cual ocasiona la violación del derecho constitucional consagrado en el artículo 76 de la Constitución.

No obstante, aceptar la posibilidad de proponer acciones extraordinarias de protección indiscriminadamente en contra de decisiones arbitrales puede ocasionar una excesiva interferencia judicial. Por lo tanto, la aplicación de las acciones extraordinarias de protección frente a declaratorias de competencia erróneas, pasa por entender que esta funciona, si y solo si los abogados que practican arbitraje utilizan la acción extraordinaria de protección de manera correcta, sin afán de dilatar el proceso innecesariamente. De esta forma, se mantiene la característica fundamental de la acción extraordinaria de protección de ser de ultima ratio. El no saturar el sistema judicial, ni constitucional requiere un autoexamen que cada uno de los abogados practicantes debe realizar.

Sin embargo, no es menos cierto que cuando una parte se ve forzada a arbitrar una disputa que no consintió, se está perpetuando una violación a su derecho al debido proceso y en este contexto, el ordenamiento jurídico no prevé una solución efectiva para tutelar este derecho. En consecuencia, la acción extraordinaria de protección resulta la única garantía jurisdiccional capaz de velar por la protección del debido proceso, tomando en cuenta que la LAM no prevé ningún otro mecanismo para impugnar esta decisión dentro del mismo proceso arbitral. 


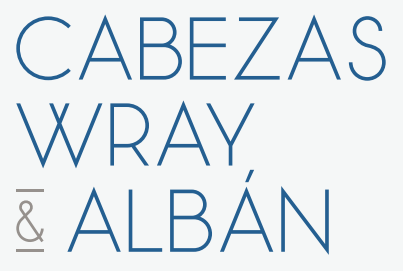

Nuestros resultados son producto de la experiencia, integridad, preparación y creatividad.

Ley de Nacional inento

$C W \bar{\Sigma} A$ Av. de los Shyris N33-134 y República del Salvador. Edificio Libertador, piso 14. Telf: (593 2) 3824613 / $3824653 / 3824693 / 3824694$ 
